\title{
Interstitial Deletions Including Chromosome 3 Common Eliminated Region I (C3CERI) Prevail in Human Solid Tumors from I 0 Different Tissues
}

\author{
Thorgunnur Eyfjord Petursdottir,' Unnur Thorsteinsdottir, ${ }^{2}$ Jon Gunnlaugur Jonasson, ${ }^{1,3}$ Pall Helgi Moller, ${ }^{4}$ \\ Chen Huiping, ${ }^{5}$ Johannes Bjornsson,' Valgardur Egilsson,' Stefan Imreh, ${ }^{6}$ and Sigurdur Ingvarsson ${ }^{5 *}$ \\ 'Department of Pathology, Landspitali University Hospital, Reykjavik, Iceland \\ ${ }^{2}$ DeCode Genetics, Reykjavik, Iceland \\ ${ }^{3}$ Icelandic Cancer Registry, The Icelandic Cancer Society, Reykjavik, Iceland \\ ${ }^{4}$ Department of Surgery, Landspitali University Hospital, Reykjavik, Iceland \\ ${ }^{5}$ Institute for Experimental Pathology, University of Iceland at Keldur, Reykjavik, Iceland \\ ${ }^{6}$ Microbiology and Tumor Biology Center (MTC), Karolinska Institutet, Stockholm, Sweden
}

\begin{abstract}
A human chromosomal segment regularly lost during tumor formation of microcell hybrids in SCID mice has been mapped to 3 p2I.3. This segment, called chromosome 3 common eliminated region I (C3CERI, also referred to as CER I), may harbor multiple tumor-suppressor genes. Because it was found that similar regions were eliminated in an inter- and intraspecies system and in two tumor types (mouse fibrosarcoma and human renal cell carcinoma), we hypothesized that the importance of C3CERI would transgress tissue specificity, that is, it could occur in tumors derived from multiple tissues. To evaluate the loss of C3CERI in various human tumor types, we conducted loss of heterozygosity (LOH) analysis of 576 human solid tumors from 10 different tissues and compared the frequency of deletion in the C3CERI area to that in two other regions on 3p: the FHIT/FRA3B region, at 3pI4.2, and the VHL region, at 3p25.3. Deletions were detected in the C3CERI region in $83 \%$ of informative tumors. Half (47\%) the LOH-positive tumors showed LOH at all informative markers, indicating a large deletion. The other half $(53 \%)$ had a discontinuous $\mathrm{LOH}$ pattern, suggesting interstitial deletions or breakpoints. The proportion of tumors with C3CERI deletions was high in all tumor types investigated, ranging from $70 \%$ to $94 \%$, except for the soft-tissue sarcomas (40\%). In the VHL and FHIT regions, deletions were observed in $73 \%$ and $43 \%$, respectively, of the tumors. Of the three $3 p$ regions analyzed, the highest deletion frequency was observed in the C3CERI region. Furthermore, we demonstrated that the interstitial deletions including C3CERI prevail over 3p/4.2-pter losses in solid tumors.
\end{abstract}

(c) 2004 Wiley-Liss, Inc.

\section{INTRODUCTION}

Chromosome 3 is abnormal in a variety of human cancers, and several candidate tumor-suppressor genes (TSGs) on 3p have been described (Braga et al., 2003; Imreh et al., 2003). Hemi- and homozygous deletions in various tumorigenic cell lines and carcinoma tissues provide further support for the presence of TSGs on 3p (Kovacs et al., 1988; Kok et al., 1994; Eiriksdottir et al., 1995; Lifu et al., 1996; Petursdottir et al., 2002).

Imreh et al. (1994) developed an assay based on nonrandom elimination of human chromosome segments in mouse-human microcell hybrids during tumor growth in SCID mice. This assay, called the elimination test (Et), was designed for the identification and fine-mapping of chromosomal regions containing putative TSGs. Microcell hybrids of either A9 mouse fibrosarcoma or human renal cell carcinoma (RCG) cell lines with an intact or partially deleted human chromosome 3 have been generated (Imreh, et al., 1994). After in vitro culti- vation and in vivo passage in SCID mice, the tumors were examined, and retained human chromosome 3 sequences were identified. By using the Et, it was possible to identify a commonly lost segment, termed chromosome 3 common eliminated region 1, or C3CER1 (referred to also as CER1; Kholodnyuk et al., 1997). A detailed transcriptional map of this region, which spans $\sim 1.4 \mathrm{Mb}$ at $3 \mathrm{p} 21.3$, has been published (Szeles et al., 1997; Yang et al., 1999; Kiss et al., 2002). According to this map, the 1.4-Mb C3CER1 region covers 19 active genes

Supported by: Science Fund of the Icelandic Cancer Society; Science Fund of Landspitali University Hospital; Memorial Fund of Bergthora Magnusdottir and Jakob B. Bjarnason.

*Correspondence to: S. Ingvarsson, Institute for Experimental Pathology, University of Iceland, Keldur v/Vesturlandsveg, 112 Reykjavik, Iceland. E-mail: siguring@hi.is

Received 19 February 2004; Accepted 25 May 2004

DOI 10.1002/gcc.20072

Published online 11 August 2004 in

Wiley InterScience (www.interscience.wiley.com). 
and 3 pseudogenes. The genes, as listed by the transcriptional map, are: KIAA0028, LIMD1, KIAA0851, XT3, LZTFL1, FYCO1, LTF, TMEM7, LRRC2, LUZP3, TDGF1, and a cluster of 8 chemokine receptors (CCRs) (Kiss et al., 2002). The functional role of these genes in tumor formation is still unknown.

The lactoferrin $(L F)$ gene is a potential TSG, as is the LIM domain containing 1 gene (LIMD1; Imreh et al., 2003). LF can suppress the growth of a fibrosarcoma cell line and of $v$-ras-transformed NIH3T3 cells, and it inhibited experimental metastasis of melanoma cells in mice (Bezault et al., 1994). In tumors derived from a fibrosarcoma A9 cell line previously transfected with either LF cDNA or the full-length $L F$ gene, $L F$ RNA expression was decreased or eclipsed. It was asserted that promoter methylation and/or chromosome rearrangements at the insertion site were responsible for this $L F$ down regulation (Yang et al., 2003). The novel LIMD1 gene identified by Kiss et al. (1999) belongs to a group of LIM domain-containing protein families that have been proposed to function in intracellular signaling pathways, transcriptional regulation, and cellular differentiation during development (Crawford et al., 1994). A tumor cell line panel was Northern blot-hybridized with LIMD1. Several truncated transcripts were detected in most of the tumor cell lines. In some cases, all 3 LIM domains were missing (Kiss et al., unpublished), suggesting its tumor-suppressor function.

Although the involvement of the CGR cluster (CCR9, STRL33, CCXCR1, CCR1, CCR3, CCR2, $C C R 5$, and $C C R L 2)$ in tumor initiation and/or progression is unclear, it is possible that the elimination of CCRs could facilitate a tumor's escape from infiltrating phagocytic macrophages or from neutrophils that secrete CCR-binding ligands. Recent findings of Manes et al. (2003) showed that CCR5 is a regulator of TP53 transcriptional activity in breast cancer cells. Blocking of CCR5 enhanced proliferation of xenografts from tumor cells with wild-type TP53.

About $3 \mathrm{Mb}$ centromeric to C3CER1 is the LUCA region, which contains several genes of interest, for example, RASSF1, HYAL1, and SEMA3B. Telomeric to C3CER1 are regions that have been detected with homozygous deletions in human malignancies (Imreh et al., 2003). Other regions on $3 \mathrm{p}$ harbor TSGs and are commonly deleted in tumors. One of these regions is the 3 p25.3 region, which contains the von HippelLindau (VHL) TSG, and another is the 3p14.2 region, which contains the FHIT TSG. Inactivation of the VHL gene is a prevalent genetic alteration in both hereditary and sporadic renal carcinomas. Frequent $\mathrm{LOH}$ and terminal $3 \mathrm{p}$ deletion including the VHL region have been reported in multiple malignancies, including renal cell, ovarian, and endometrial carcinomas (Maynard and Ohh, 2004).

The FHIT gene, at 3p14.2, contains a common fragile site, FRA3B. We previously investigated LOH frequency at the FHIT locus, using the same tumor material as used in the current investigation. In the previous study, LOH at the FHIT gene affecting at least one of the six analyzed markers was detected in half the informative tumors, ranging from $30 \%$ to $66 \%$, depending on tumor location (Ingvarsson et al., 2001; Petursdottir et al., 2002). $\mathrm{LOH}$ at all the informative FHIT markers was more prevalent than breakpoints, suggesting a large deletion. Thus, these data indicated that LOH at the FHIT gene is a fairly common event in all the tumor types analyzed. However, the question remained whether the $\mathrm{LOH}$ resulted from mitotic nondisjunction, mitotic recombination between the homologues or nonhomologues, or gene conversions, or whether the LOH disclosed terminal or interstitial deletions. The presence of the FRA3B may suggest that terminal deletions occur frequently and may lead to 3 p14.2-pter losses. The pericentromeric $3 \mathrm{p} 10-\mathrm{p} 11$ region has preferential breakpoints in many solid tumors that may lead to entire $3 p$ losses, as has been proven in model systems as well as by analysis of databases (KostAlimova et al., 2004).

In this investigation, we addressed the question whether the C3CER1 region at 3p21.3 is preferentially lost in human tumors, as was evident using the Et model system (Imreh et al., 1994). We also sought to determine whether the fragile nature of FRA3B induces terminal deletions leading to 3 p14.2-pter losses or whether the eventual 3p21.3 losses are interstitial. We analyzed and compared the frequency of deletion of the C3CER1 region with that in two other tumor-suppressor regions on 3p: the 3p14.2 region, which contains the FHIT, and the VHL region, which maps near the telomere to $3 \mathrm{p} 25.3$. Because the tumor material used in the current investigation of $\mathrm{LOH}$ in the $3 \mathrm{p} 25.3$ and 3 p21.3 regions was the same as that used in our previous study of LOH at the FHIT locus (Ingvarsson et al., 2001; Petursdottir et al., 2002), we used the previous data for comparison of $\mathrm{LOH}$ frequency. Our results suggest that chromosomal deletions at C3CER1 are a highly common event in multiple human tumors and that interstitial deletions prevail. 
MATERIALS AND METHODS

\section{Patients and Tumor Material}

Samples from 576 primary solid tumors and matching nonmalignant tissue were obtained on the day of surgery. The samples were immediately frozen at $-70^{\circ} \mathrm{C}$. The organs from which the tumors came and the number of each were: breast (159), stomach (38), colon/rectum (115), lung (70), endometrium (25), ovaries (42), testicles (31), kidney (67), thyroid gland (14), and soft-tissue sarcomas (15). All information on the tumors was recorded at the Department of Pathology, Landspitali University Hospital, Iceland.

\section{DNA Extraction and PCR}

Tumor and normal DNA was extracted from the tissue samples with proteinase $\mathrm{K}$ using a method developed for paraffin-embedded tissue (Smith et al., 1992). Paired samples of tumor and normal DNA were subjected to PCR analysis. DynaZyme $^{\mathrm{TM}}$ polymerase (from Finnzymes Oy, Espoo, Finland) was used in the buffer solution provided by the manufacturer. Samples were denatured for $3 \mathrm{~min}$ at $95^{\circ} \mathrm{C}$ and then subjected to 35 cycles of amplification consisting of $30 \mathrm{sec}$ at $95^{\circ} \mathrm{C}$, $30 \mathrm{sec}$ at $55^{\circ} \mathrm{C}-60^{\circ} \mathrm{C}$, and $60 \mathrm{sec}$ at $72^{\circ} \mathrm{C}$, followed by $10 \mathrm{~min}$ at $72^{\circ} \mathrm{C}$.

The microsatellite markers in the C3CER1 region that were used were D3S3582, D3S2354, AFMB362WB9, GAAT-p33715, and D3S1767. D3S3582 is centromeric to the RIS1 gene, near LARS2; $D 3 S 2354$ is in a terminal intron of LARS2; $A F M B 362 W B 9$ is between two CCRs, CCXCR1 and CGR1; GAAT-p33715 is between LF and TMEM7; and D3S1767, already outside CER1, is near the $M G C 2391 B$ gene. Therefore, of the five markers, four are within C3CER1, and one (D3S1767) is about $0.3 \mathrm{Mb}$ outside the region toward the centromere. The C3CER1 region covered by the markers is a total of $1.5 \mathrm{Mb}$.

As a control, we used three markers (D3 $\$ 4545$, $D 3 S 1317$, and D3S1335) that map to $3 \mathrm{p} 25.3$; these markers cover $1.7 \mathrm{Mb}$ of DNA around the VHL region (Fig. 1). Also as a control, we used the published results on four microsatellite markers within the FHIT gene, covering $0.67 \mathrm{Mb}$ (Ingvarsson et al., 2001; Petursdottir et al., 2002). According to the Ensembl genome browser at the Sanger Center, the markers in the VHL region that were used are external to the VHL gene and cover at least 29 genes. The C3CER1 region markers used cover 19 active genes and 3 pseudogenes, and the FHIT markers are all within the FHIT gene.

\section{LOH Analysis}

The PCR products were separated on $6.5 \%$ polyacrylamide $8 \mathrm{M}$ urea gels in $1 \times$ TBE buffer for 3-4 hr at $60 \mathrm{~W}$. After electrophoresis, the PCR products were transferred to a Hybond- ${ }^{+}$nylon membrane (Amersham Pharmacia Biotech, Buckinghamshire, UK). Primers were elongated by terminal-transferase in $40 \mathrm{mM} \mathrm{K}$-HEPES/1 $\mathrm{mM}$ $\mathrm{CoCl}_{2}$ buffer at $\mathrm{pH} 7.2$ and $37^{\circ} \mathrm{C}$ overnight to facilitate the binding of peroxidase to the probe (Vignal et al., 1993). The Hybond- ${ }^{+}$membranes were then hybridized for at least $2 \mathrm{hr}$ at $42^{\circ} \mathrm{C}$ with elongated primers and covalently labeled with peroxidase (ECL labeling kit, Amersham Pharmacia Biotech). After hybridization, the membranes were washed once for $20 \mathrm{~min}$ in $3 \times \mathrm{SSC} / 0.1 \% \mathrm{SDS}$ at $42^{\circ} \mathrm{C}$ and then twice for $15 \mathrm{~min}$ in $0.2 \times \mathrm{SSC}$ at $42^{\circ} \mathrm{C}$. Finally, the membranes were bathed in a detection reagent containing $\mathrm{H}_{2} \mathrm{O}_{2}$, luminol, and an enhancer (ECL detection kit, Amersham Pharmacia Biotech) for $1 \mathrm{~min}$ at room temperature, and signals were detected on AGFA Cronex-5 film. Films were inspected visually; any absence or significant decrease in the intensity of one allele relative to the other was considered $\mathrm{LOH}$.

\section{RESULTS}

\section{LOH Analysis of the 3p2I.3 (C3CERI) Region}

The microsatellite polymorphism at the C3CER1 locus was analyzed by screening 576 human solid tumors using five C3CER1 microsatellite markers (Fig. 1). The majority (408) of analyzed samples were informative for the C3CER1 markers. As presented in Figure 2, we detected LOH for at least one C3CER1 marker in $339(83 \%)$ of the 408 informative tumors. All informative C3CER1 markers were deleted in 158 (47\%) of the LOH-positive tumors, indicating a large deletion. The remaining 181 tumors with $\mathrm{LOH}$ had a discontinuous $\mathrm{LOH}$ pattern, suggesting interstitial deletions, or breakpoints, in the C3CER1 region. The LOH frequency for at least one marker was high, ranging from $70 \%$ to $94 \% \mathrm{LOH}$, in tumors from all locations except for the soft-tissue sarcomas, the proportion of which that had LOH was only $40 \%$ (Fig. 2). It should be noted, however, that the sample size analyzed for endometrial and thyroid tumors as well as soft-tissue sarcomas was rather small, explaining less significant results (Table 1). There was a difference in the observed LOH frequency for individual C3CER1 markers depending on tumor location. The highest was $80 \%$ at the GAATp33715 marker in testis tumors, and the lowest was 


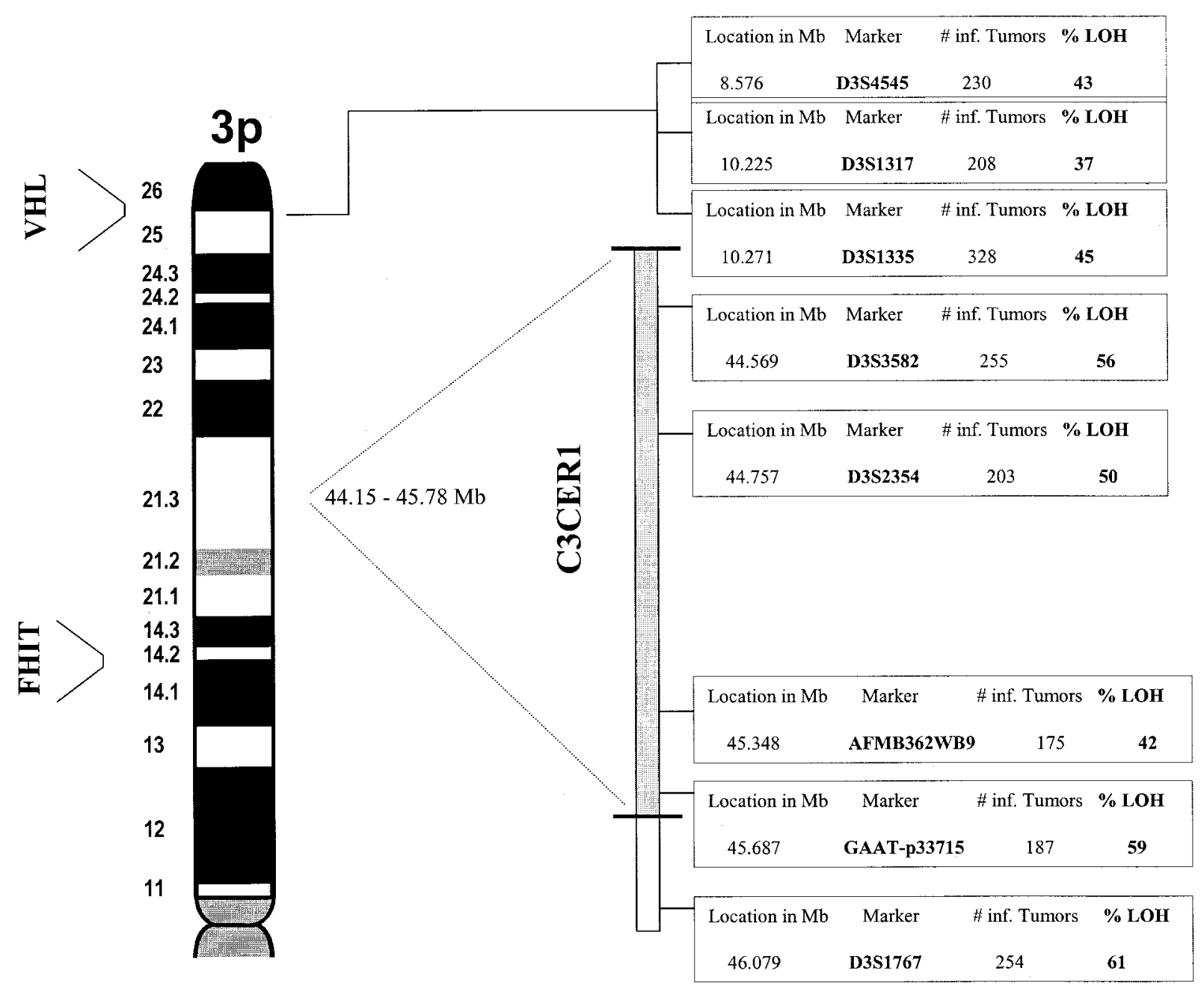

Figure I. Schematic representation of $3 p$ with the locations of markers used in this study. The C3CERI region at 3p2I.3 and the chromosomal area it spans are shown in megabases from the telomere, as is information on marker location. The number of informative samples and the proportion of tumors with $\mathrm{LOH}$ are given for each marker.

$0 \%$, which occurred at the same marker in endometrial tumors and at the AFMB362WB9 marker in thyroid tumors (Fig. 3).

\section{LOH Analysis of the 3p25.3 (VHL) Region}

As a control and to assess the dimension of the critical region as well as to determine if our results suggested terminal or interstitial deletions, we compared LOH frequency in the C3CER1 region to that in two other regions on $3 \mathrm{p}$. One region was 3 25.3, where the VHL tumor-suppressor gene resides. We used three microsatellite markers mapped around the VHL gene (Fig. 1). Only 320 (of 576) tumors were informative (Table 1), and of these, $232(73 \%)$ had deletions at the site of at least one VHL marker (Fig. 4). Of the 232 LOH tumors, 126 had LOH at all informative VHL markers.
Therefore, $106(54 \%)$ of the LOH tumors had a discontinuous LOH pattern. The deletion frequency in the VHL region was high in tumors from all analyzed organs, ranging from $63 \%$ in stomach tumors to $93 \%$ in kidney tumors (Fig. 4).

\section{Comparison of LOH Frequency at C3CERI to VHL and FHIT}

The total LOH frequency (of all tumor types pooled together) in the C3CER1 region was significantly higher than the LOH frequency in both the FHIT (data from our previous studies: Ingvarsson et al., 2001; Petursdottir et al., 2002) and the VHL regions $(P<0.05$ in both cases; Fig. 5). Similarly, the total LOH frequency at the FHIT locus was significantly lower than that at the VHL locus $(P<0.05)$. If the tumors were separated according to organ type, 


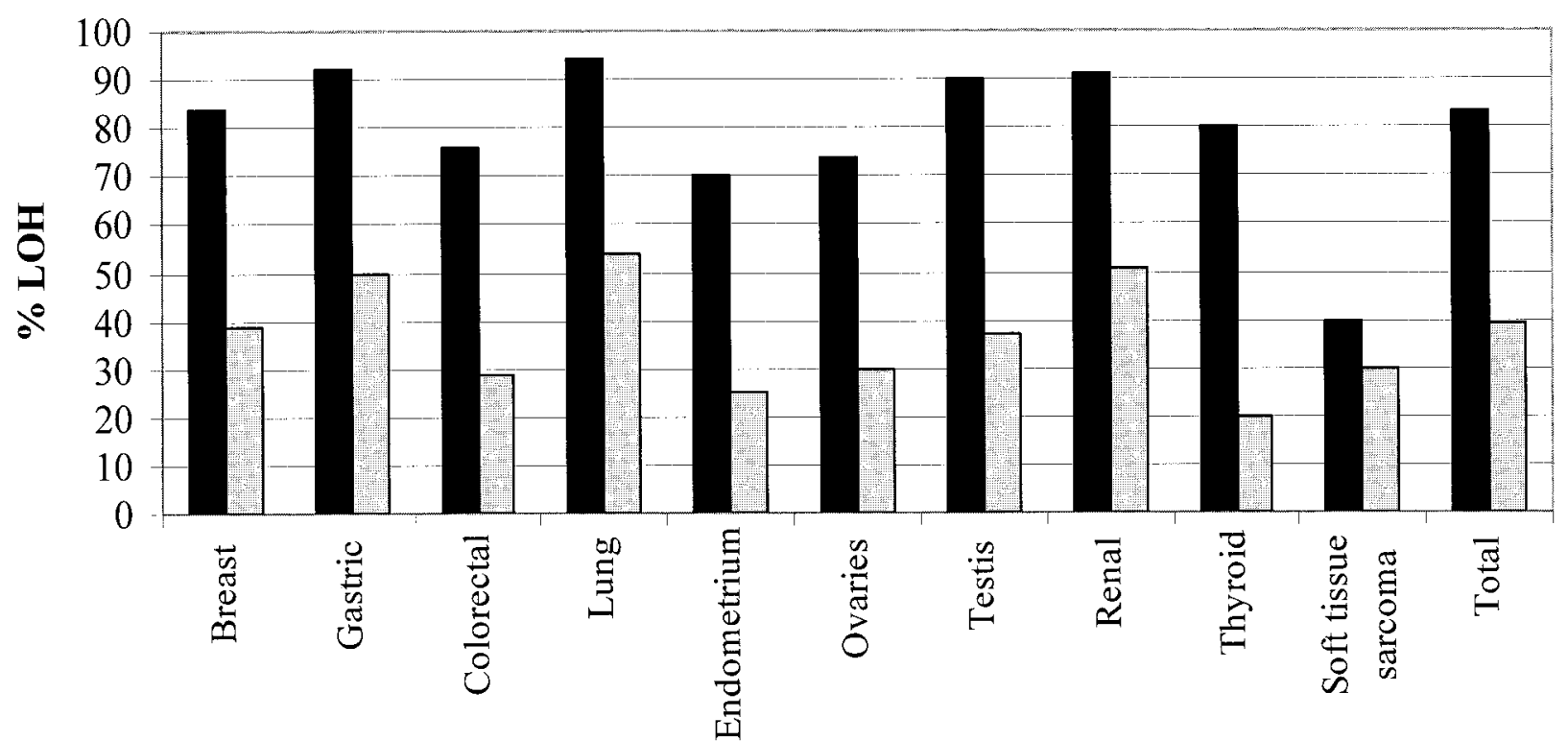

Tumors

\title{
C3CER1 LOH at one or more markers $\square$ C3CER1 LOH at all informative markers
}

\begin{abstract}
Figure 2. Graphic presentation of C3CERI LOH frequency in tumors from 10 different tissues. Shown are the percentages of samples with LOH of at least one (black bar) or all of the informative markers (gray bars).
\end{abstract}

$\mathrm{LOH}$ frequency in the C3CER1 region was significantly higher $(P<0.05)$ than that at the FHIT locus in all tumor types except in tumors with a low sample number, that is, endometrial and thyroid tumors and soft-tissue sarcoma. The deletion frequency was higher in the C3CER1 region than at the VHL locus in all tumor types analyzed except for endometrial, ovarian, and renal tumors and soft-tissue sarcoma (Fig. 5). However, this difference was significant $(P<$ 0.05 ) in only three tumor types: breast, gastric, and lung. The deletion frequency at the VHL locus in all the investigated tumor types was higher than that observed for FHIT and was statistically significant in breast, colorectal, ovary, and renal tumors and in sarcomas (Fig. 5).

\section{Breakpoint Analysis of the C3CERI and VHL Regions}

In tumors with a discontinuous $\mathrm{LOH}$ pattern, breakpoints can be located within the region analyzed. Thus, with the exception of the thyroid tumors and the soft-tissue sarcomas, we were able to locate breakpoints in the C3CER1 region in $44-64 \%$ of the samples that had LOH (Table 2). Our results suggest hot-spot regions for breakage between markers D3S3582 and D3S2354 and between GAAT-p33715 and D3S1767, that is, toward both ends of the C3CER1 region (Fig. 6a).
Breakpoints in the VHL region were located in $19-67 \%$ of tumors with LOH (Table 3), again excluding thyroid tumors and soft-tissue sarcomas. D3S1335 and D3S1317 are both close to the VHL gene, 0.87 and $0.41 \mathrm{Mb}$ downstream, respectively. D3S4545 is much farther from the VHL gene, approximately $1.6 \mathrm{Mb}$ upstream. Even though the area covered by D3S1335 and D3S1317 is significantly smaller, we found nearly twice as many breakpoints as were found between D3S1317 and D3S4545: 56 versus 32 breakpoints, respectively (Fig. 6b).

To determine the prevalence of loss of the whole $3 p$ or of $3 p 14.2-$ pter deletions, we analyzed the proportion of tumors that showed loss of all informative markers typed in the three investigated regions. Of the 417 samples analyzed (not including breast samples), 208 were informative for all the markers in the three regions analyzed. Of these tumor samples, only 27 , or $13 \%$, had lost all informative markers at all the $3 \mathrm{p}$ loci investigated (results not shown), suggesting that loss of the whole $3 p$ arm or 3p14.2-pter deletions is relatively rare and that the $3 p$ losses are predominantly interstitial deletions.

\section{DISCUSSION}

The Et is an assay designed for the identification and fine-mapping of chromosomal regions containing putative TSGs (Imreh et al., 1994). Using this 


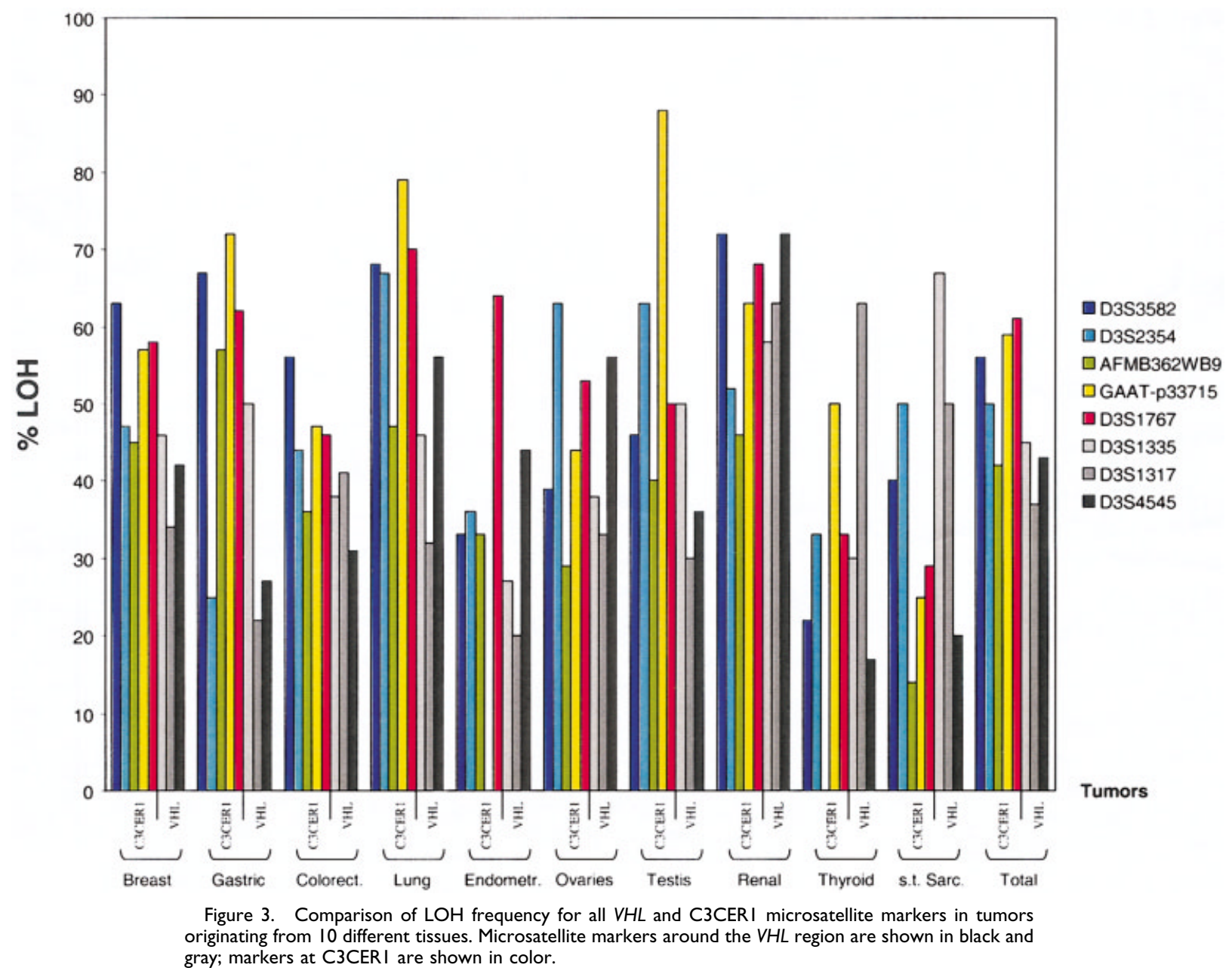

TABLE I. Total Number of Tumors for Each Tissue and Number of Tumors Informative for C3CERI and VHL Markers

\begin{tabular}{lccc}
\hline Tumor location & $\begin{array}{c}\text { Number } \\
\text { of } \\
\text { tumors }\end{array}$ & $\begin{array}{c}\text { C3CERI } \\
\text { informative } \\
\text { tumors (\%) }\end{array}$ & $\begin{array}{c}\text { VHL } \\
\text { informative } \\
\text { tumors (\%) }\end{array}$ \\
\hline Breast & 159 & $127(80)$ & $114(72)$ \\
Gastric & 38 & $26(68)$ & $16(42)$ \\
Colorectal & 115 & $76(66)$ & $53(46)$ \\
Lung & 70 & $52(74)$ & $39(56)$ \\
Endometrium & 25 & $20(80)$ & $12(48)$ \\
Ovary & 42 & $23(55)$ & $22(52)$ \\
Testis & 31 & $19(61)$ & $16(52)$ \\
Renal & 67 & $45(67)$ & $28(42)$ \\
Thyroid & 14 & $10(71)$ & $10(71)$ \\
Soft-tissue sarcoma & 15 & $10(67)$ & $10(67)$ \\
Total & 576 & $408(71)$ & $320(56)$ \\
\hline
\end{tabular}

assay, a regularly deleted region of 3p21.3, C3CER1, was identified. The transcriptional map of C3CER1, containing 19 genes, has been published (Kiss et al.,
2002). The Et was initially performed using human chromosome 3/mouse fibrosarcoma (Imreh et al., 1994, 2003), then continued with human chromosome 3/human RCC material (Yang et al., 2001). In both systems, similar eliminated regions have been detected. This suggests that the importance of genomic losses including that of C3CER1 transgresses species and tissue specificity and may occur nonrandomly in tumors derived from multiple tissues. To investigate the validity of this hypothesis, we conducted an $\mathrm{LOH}$ analysis, using reliable tumor material of 576 human solid tumors from 10 different tissues. To assess the dimension of the critical region and to determine whether the fragile nature of $F R A 3 B$ at 3 p14.2 induces terminal deletions leading to 3 p14.2-pter loss, we compared the deletion frequency of this area to two other tumor-suppressor regions on 3p, namely, the FHIT region, at 3p14.2, and the VHL region, at $3 \mathrm{p} 25.5$.

Of the 576 tumors analyzed, 408 were informative for the C3CER1 markers used. A total of 339 


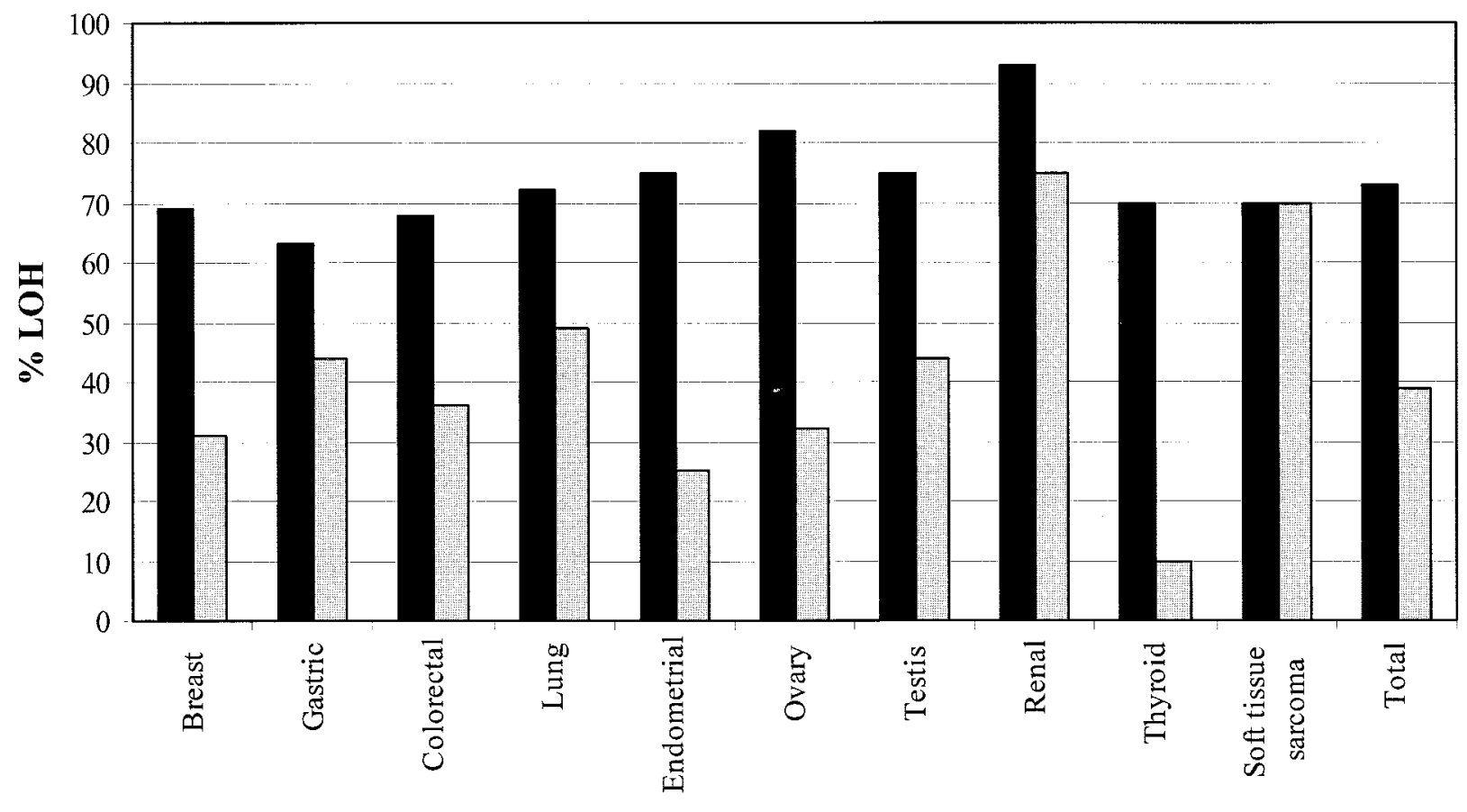

Tumors

- VHL region $\mathrm{LOH}$ one or more markers $\square$ VHL region $\mathrm{LOH}$ at all informative markers

Figure 4. Graphic presentation of $V H L L O H$ frequency in tumors from 10 different tissues. Shown are the percentages of samples with LOH of at least one (black bar) or all of the informative markers (gray bars).

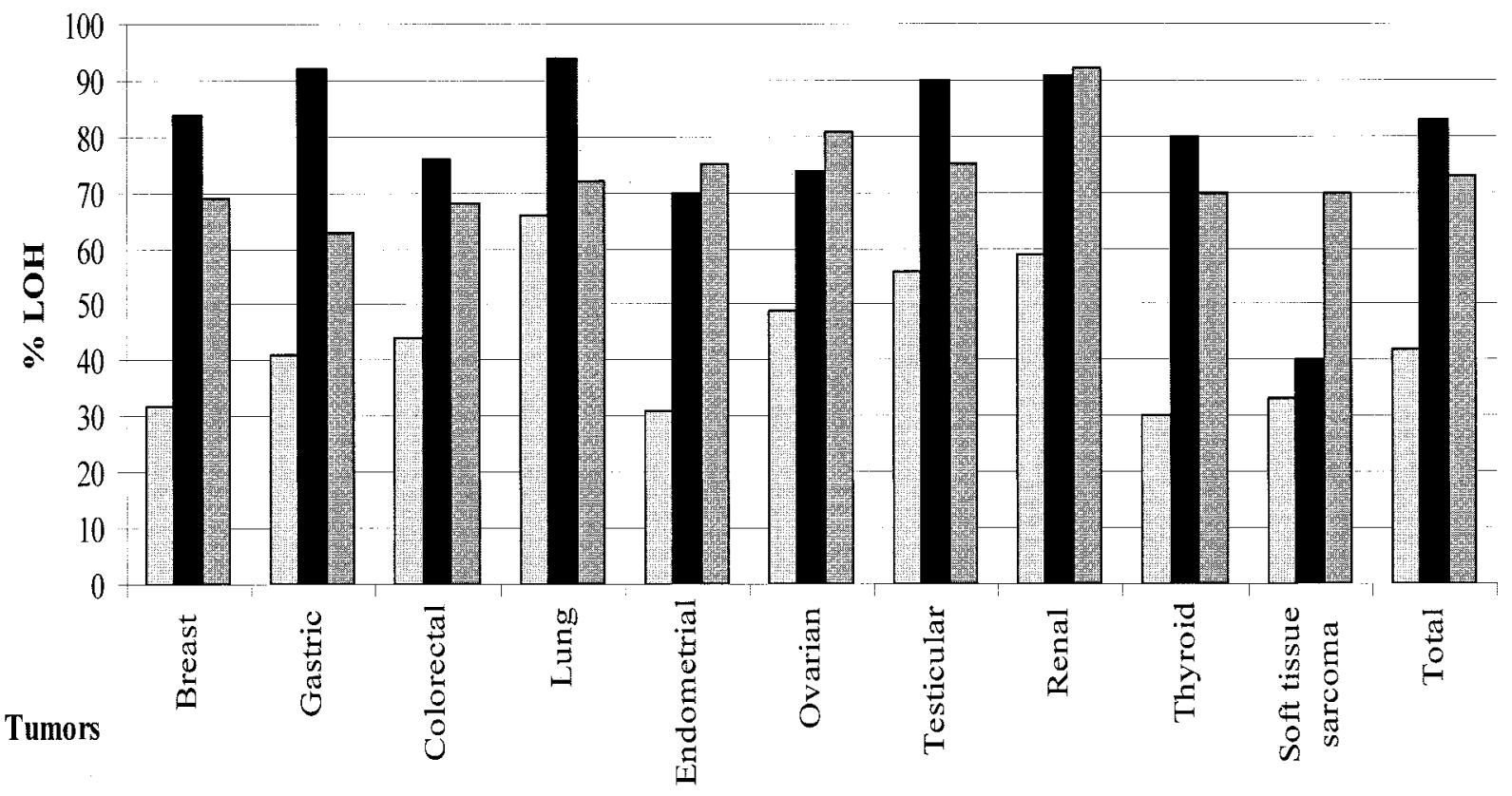

DFHIT DC3CER1 圆 VHL region

Figure 5. Comparison of LOH frequency of at least one marker at three 3p regions. The FHIT gene is at 3 p 4.2 (light gray bars), the C3CERI region is at 3p2I.3 (black bars), and the VHL region (dark gray bars) is at $3 \mathrm{p} 25.3$. 


\section{a) C3CER1 region}

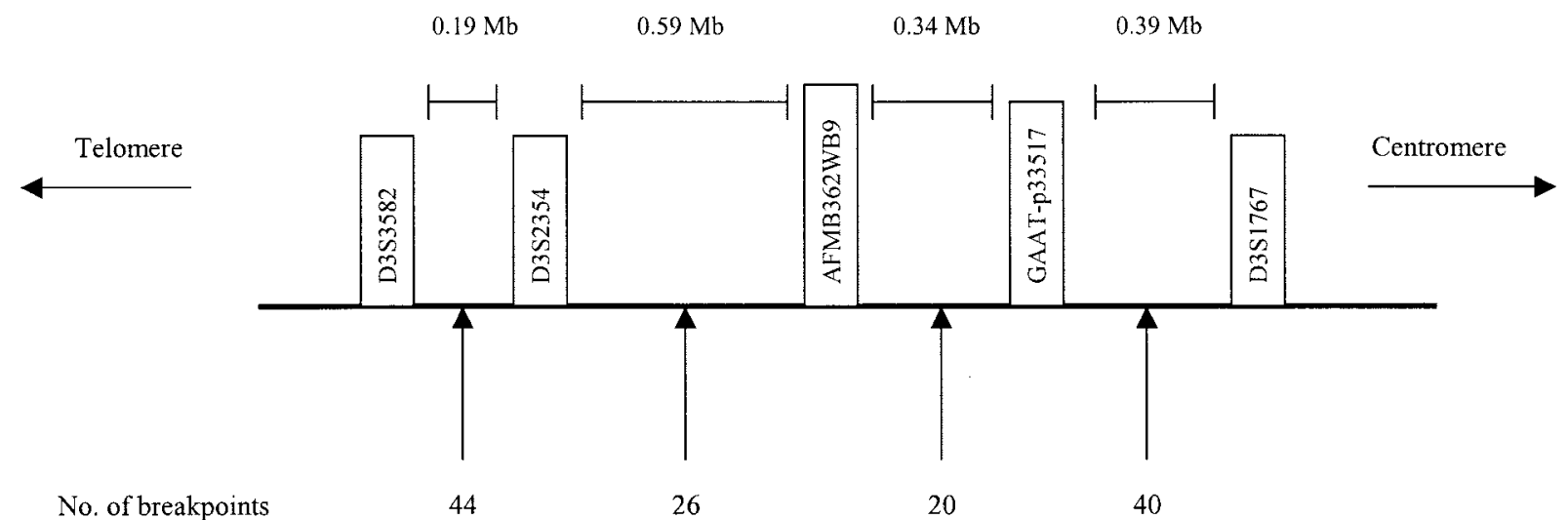

b) VHL region

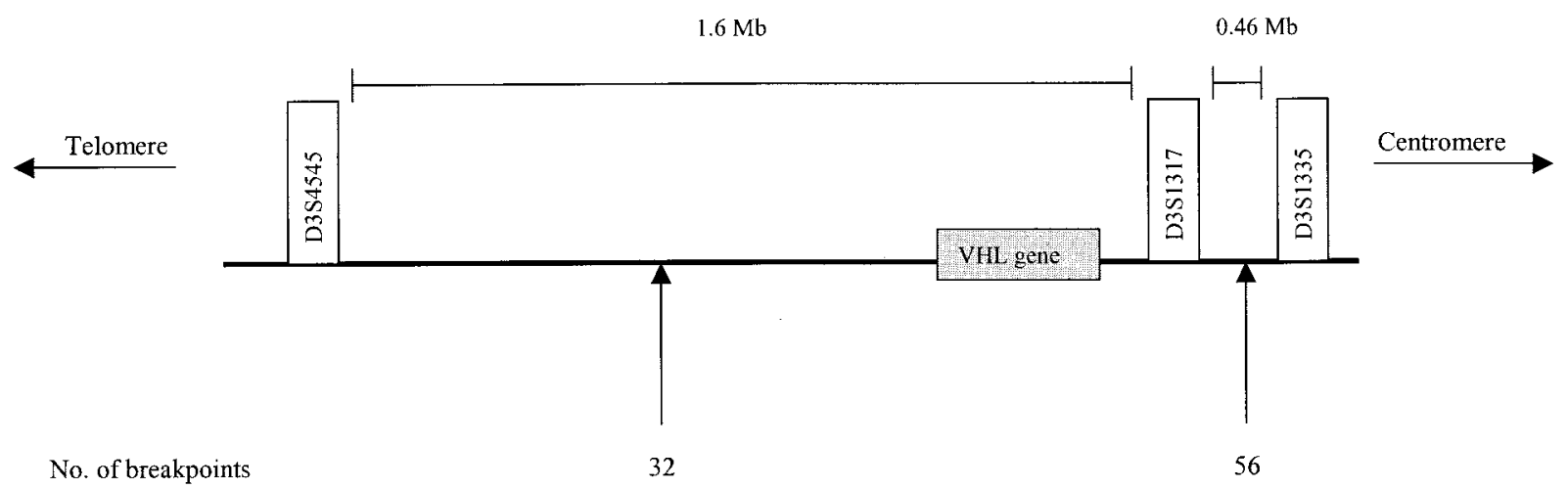

Figure 6. The location and number of identifiable breakpoints. Distance between markers is shown in megabases. (a) C3CERI region (339 informative samples), in which the breakpoints cluster toward both of this region's borders. (b) VHL region (220 informative samples) with approximate location of the VHL gene

shown. Breakpoints are more common downstream of the VHL gene (toward centromere) than upstream of it.

TABLE 2. Percentage of Located Breakpoints in the C3CERI Region

\begin{tabular}{lcccc}
\hline Tumor locations & $\begin{array}{c}\text { Number of LOH } \\
\text { samples }\end{array}$ & $\begin{array}{c}\text { Number of LOH samples } \\
\text { with breakpoints within } \\
\text { C3CERI }\end{array}$ & $\begin{array}{c}\text { Breakpoints between } \\
\text { C3CERI markers } \\
(\%)\end{array}$ & $\begin{array}{c}\text { Breakpoints outside } \\
\text { C3CERI markers } \\
(\%)\end{array}$ \\
\hline Breast & 107 & 57 & 53 & 47 \\
Gastric & 24 & 11 & 46 & 54 \\
Colorectal & 58 & 36 & 62 & 38 \\
Lung & 49 & 22 & 45 & 55 \\
Endometrium & 14 & 9 & 64 & 36 \\
Ovary & 17 & 10 & 59 & 41 \\
Testis & 17 & 10 & 59 & 41 \\
Renal & 41 & 18 & 44 & 56 \\
Thyroid & 8 & 6 & 25 & 25 \\
Soft-tissue sarcoma & 4 & 1 & 53 & 75 \\
Total & 339 & 180 & & 47 \\
\hline
\end{tabular}

tumors had $\mathrm{LOH}$ with at least one marker. Of these, 158 showed $\mathrm{LOH}$ with all the informative markers, possibly as a result of a larger deletion. The remaining $181 \mathrm{LOH}$ tumors showed a discontinuous LOH pattern, in which case breakpoints could be located using the analyzed markers in the C3CER1 region. Only 320 tumors were informative for the three VHL markers used. More than two-thirds had deletions at one or more markers. Approximately half the LOH tumors had lost all 
TABLE 3. Percentage of Located Breakpoints Around the VHL Region

\begin{tabular}{lcccc}
\hline Tumor locations & $\begin{array}{c}\text { Number of LOH } \\
\text { samples }\end{array}$ & $\begin{array}{c}\text { Number of LOH samples with } \\
\text { breakpoints around VHL }\end{array}$ & $\begin{array}{c}\text { Breakpoints between } \\
\text { VHL markers (\%) }\end{array}$ & $\begin{array}{c}\text { Breakpoints outside } \\
\text { VHL markers (\%) }\end{array}$ \\
\hline Breast & 79 & 44 & 56 & 44 \\
Gastric & 10 & 3 & 30 & 70 \\
Colorectal & 36 & 17 & 47 & 53 \\
Lung & 28 & 9 & 32 & 68 \\
Endometrium & 9 & 6 & 67 & 33 \\
Ovary & 18 & 11 & 61 & 58 \\
Testis & 12 & 5 & 42 & 81 \\
Renal & 26 & 5 & 19 & 14 \\
Thyroid & 7 & 6 & 86 & 0 \\
Soft-tissue sarcoma & 7 & 0 & 41 & 59 \\
Total & 220 & 90 & & \\
\hline
\end{tabular}

informative markers; the other half had a discontinuous $\mathrm{LOH}$ pattern. The deletion frequency in the $V H L$ region was high in tumors from all of the analyzed organs.

D3S1767 is about $0.3 \mathrm{Mb}$ outside the centromeric border of C3CER1 toward the LUCA region described by Lerman and Minna (2000). The LUCA region is an interesting segment at $3 \mathrm{p} 21.3$; it is defined by homozygous deletions in small cell lung carcinoma, non-small cell lung carcinoma, breast, kidney, and other carcinomas and contains 25 genes (Lerman and Minna, 2000), at least 7 of which are candidate TSGs, with RASSF 1 the most suggestive so far (Imreh et al., 2003). The observed LOH at the D3S1767 marker was high, suggesting that $\mathrm{LOH}$ in this tumor material could also be high for the LUCA region, prompting further analysis using this material.

Comparing LOH frequency in the C3CER1 region to that at other loci was an important control. This allowed us to deduce whether the LOH frequency was in fact elevated in this particular area. One locus that we used as a control is FHIT, a TSG at $3 \mathrm{p} 14.2$. An aphidicolin-sensitive common fragile site (FRA3B) maps within the FHIT gene, which makes it susceptible to chromosomal breakage and rearrangements; therefore, FHIT can be linked to hyperinstability. Although a number of studies have demonstrated FHIT to have a tumor-suppressor function (Siprashvili et al., 1997; Ji et al., 1999; Sard et al., 1999; Werner et al., 2000; Dumon et al., 2001; Ishii et al., 2001; Zanesi et al., 2001), the relatively high $\mathrm{LOH}$ frequency that we observed in our previous studies (Ingvarsson et al., 2001; Petursdottir et al., 2002) could be, at least in part, a result of the naturally occurring fragility of the area. Given that the FHIT locus at 3p14.2 is classified as fragile (see below) and that the LOH frequency at
C3CER1 is significantly higher than at the FHIT gene strongly suggest that $\mathrm{LOH}$ at C3CER1 is a causative element in tumor development rather than a reflection of an unstable genome in tumor cells. Furthermore, our results suggest that only $13 \%$ of any 3 p14.2-pter loss in our tumor material could possibly result from breakage in the FHIT/ FRA3B region (all informative markers at the 3 regions analyzed lost).

According to Richards (2001), the C3CER1, at $3 \mathrm{p} 21.3$, is not a genomic region classified as a fragile site, that is, it does not meet the criterion of being fragile under conditions that cause late replication. However, the centromeric segment of the C3CER1 has been shown to contain a murine/ human conservation breakpoint region (CBR), which means that the equivalent region in the mouse is split into two segments on mouse chromosome 9. The CBR region has instability features because it is regularly deleted in YACs, it has gene duplications and pseudogenes, and it has an elevated frequency of long terminal repeat insertions and a hairpin-forming TATAGA repeat that may be associated with deletions. It also was observed, using a FISH-based replication-timing analysis, that DNA replication of the CBR region is delayed (Kost-Alimova et al., 2003). Assuming that both the FHIT and the C3CER1 regions have features that predispose to fragility, although on a different background, we can conclude that loss of the C3CER1 imparts additional selective growth advantage.

Breakpoint is a term used to identify juxtaposed regions in which one region has $\mathrm{LOH}$ and the other has ROH (retention of heterozygosity). We found that approximately half the tumors with $\mathrm{LOH}$ in the C3CER1 and VHL regions had a discontinuous $\mathrm{LOH}$ pattern. One third of tumors with discontin- 
uous deletions in the C3CER1 region had retained one or more markers around the VHL gene. There appear to be hot-spot regions for breakage toward both ends of the C3CER1 region. This could reflect a synergism of TSG loss in the C3CER1 region with tumor pathogenesis.

The D3S1335 and D3S1317 markers are both close to the VHL gene, 0.87 and $0.41 \mathrm{Mb}$ downstream, respectively. D3S4545 is approximately 1.6 $\mathrm{Mb}$ upstream from the gene. Therefore, if deletions were random in this region, we would expect breakpoints to be more common between D3S1317 and D3S4545 (which are more than 1.6 Mb apart) than between D3S1317 and D3S1335 (which are only $0.46 \mathrm{Mb}$ apart). However, we found the opposite to be true. Almost twice as many breakpoints were found between markers D3S1335 and D3S1317 as found between D3S1317 and D3S4545 (Fig. 6), implying that breakage occurring near the VHL gene confers a greater growth advantage for tumors than does breakage telomeric to the gene. It would be of interest to analyze the DNA sequence in these breakpoint regions in order to define elements responsible for the breakage.

Several TSGs seem to be located at $3 \mathrm{p} 21.3$ that could be targets in some cancers but not in others. The high number of genes in the C3CER1 and $V H L$ regions possibly could explain in part why the $\mathrm{LOH}$ is so high there compared to that in the FHIT region.

Taken together, our data indicate that LOH in the C3CER1 region was more frequent than was $\mathrm{LOH}$ in either the FHIT or the VHL regions in the vast majority of the 10 tumor types analyzed. $\mathrm{LOH}$ at C3CER1 was widespread in all tumor types investigated, indicating that C3CER1 deletions transgress tissue specificity. Still, it cannot be excluded that certain deletions may be characteristic of a specific tumor type. Furthermore, we showed that only $13 \%$ of the tumors had lost all informative $3 \mathrm{p}$ markers, demonstrating that interstitial deletions including deletions in C3CER1 prevailed.

\section{REFERENCES}

Bezault J, Bhimani R, Wiprovnick J, Furmanski P. 1994. Human lactoferrin inhibits growth of solid tumors and development of experimental metastases in mice. Cancer Res 54:2310-2312.

Braga EA, Kashuba VI, Malyukova AV, Loginov VI, Senchenko VN, Bazov IV, Kisselev LL, Zabarovsky ER. 2003. New tumor suppressor genes in hot spots of human chromosome 3: New methods of identification. Mol Biol 37:170-185.

Crawford AW, Pino JD, Beckerle MC. 1994. Biochemical and molecular characterization of the chicken cysteine-rich protein, a developmentally regulated LIM-domain protein that is associated with the actin cytoskeleton. J Cell Biol 124:117-127.

Dumon KR, Ishii H, Fong LY, Zanesi N, Fidanza V, Mancini R, Vecchione A, Baffa R, Trapasso F, During MJ, Huebner K, Croce CM. 2001. FHIT gene therapy prevents tumor development in Fhit-deficient mice. Proc Natl Acad Sci USA 98:3346-3351.
Eiriksdottir G, Bergthorsson JT, Sigurdsson H, Gudmundsson J, Skirnisdottir S, Egilsson V, Barkardottir RB, Ingvarsson S. 1995. Mapping of chromosome 3 alterations in human breast cancer using microsatellite PCR markers: correlation with clinical variables. Int J Oncol 6:369-375.

Imreh S, Kholodnyuk I, Allikmetts R Stanbridge EJ, Zabarovsky ER, Klein G. 1994. Nonrandom loss of human chromosome 3 fragments from mouse-human microcell hybrids following progressive growth in SCID mice. Genes Chromosomes Cancer 11: 237-245.

Imreh S, Klein G, Zabarovsky ER. 2003. Search for unknown tumor antagonizing genes. Genes Chromosomes Cancer 38:307-321.

Ingvarsson S, Sigbjornsdottir BI, Huiping C, Jonasson JG, Agnarsson BA. 2001. Alterations of the FHIT gene in breast cancer: association with tumor progression and patient survival. Cancer Detect Prev 25:292-298.

Ishii H, Dumon KR, Vecchione A, Trapasso F, Mimori K, Alder H, Mori M, Sozzi G, Baffa R, Huebner K, Croce CM. 2001. Effect of adenoviral transduction of the fragile histidine triad gene into esophageal cancer cells. Cancer Res 61:1578-1584.

Ji L, Fang B, Yen N, Fong K, Minna JD, Roth JA. 1999. Induction of apoptosis and inhibition of tumorigenicity and tumor growth by adenovirus vector-mediated fragile histidine triad (FHIT) gene overexpression. Cancer Res 59:3333-3339.

Kholodnyuk I, Kost-Alimova M, Kashuba V, Szeles A, Stanbridge EJ, Zabarovsky ER, Klein G, Imreh S. 1997. A 3p21.3 region is preferentially eliminated from human chromosome $3 /$ mouse microcell hybrids during tumor growth in SCID mice. Genes Chromosomes Cancer 18:200-211.

Kiss H, Kedra D, Yang Y, Kost-Alimova M, Kiss C, O'Brien KP, Fransson I, Klein G, Imreh S, Dumanski JP. 1999. A novel gene containing LIM domains (LIMD1) is located within the common eliminated region 1 (G3CER1) in 3p21.3. Hum Genet 105:552-559.

Kiss H, Yang Y, Kiss C, Andersson K, Klein G, Imreh S, Dumanski JP. 2002. The transcriptional map of the common eliminated region 1 (C3CER1) in 3p21.3. Eur J Hum Genet 10:52-61.

Kok K, van den Berg A, Veldhuis PM, van der Veen Ay, Franke M, Schoenmakers EF, Hulsbeek MM, van der Hout AH, de Leij L, van de Ven W. 1994. A homozygous deletion in a small cell lung cancer cell line involving a 3 p21 region with a marked instability in yeast artificial chromosomes. Cancer Res 54:4183-4187.

Kost-Alimova M, Kiss H, Federova L, Yang Y, Dumanski JP, Klein $G$ and Imreh S. 2003. Coincidence of synteny breakpoints with malignancy-related deletions on human chromosome 3. Proc Natl Acad Sci USA 100:6622-6627.

Kost-Alimova M, Fedorova L, Yang Y, Klein G, Imreh S. 2004. Microcell mediated chromosome transfer provides evidence that polysomy promotes structural instability in tumor cell chromosomes through asynchronous replication and breakage within late replicating regions. Genes Chromosomes Cancer, 40:316-324.

Kovacs G, Erlandsson R, Boldog F, Ingvarsson S, Müller-Brechlin R, Klein G, Sümegi J. 1988. Consistent chromosome 3p deletion and loss of heterozygosity in renal cell carcinoma. Proc Natl Acad Sci USA 85:1571-1575.

Lerman MI and Minna JD, The International Lung Cancer Chromosome 3p21.3 Tumor Suppressor Gene Consortium. 2000. The $630 \mathrm{~kb}$ lung cancer homozygous deletion region on human chromosome 3p21.3: identification and evaluation of the resident candidate tumor suppressor genes. Cancer Res 60:6116-6133.

LiFu Hu, Eiriksdottir G, Lebedeva T, Kholodnyouk I, Alimov A, Chen F, Luo Y, Zabarovsky ER., Ingvarsson S, Klein G, Ernberg I. 1996. Loss of heterozygosity on chromosome arm 3p in nasopharyngeal carcinoma. Genes Chromosomes Cancer 17:118-126.

Manes S, Mira E, Colomer R, Montero S, Real LM, Gomez-Mouton C, Jimenez-Baranda S, Garzon A, Lacalle RA, Harshman K, Ruiz A, Martinez C. 2003. CCR5 expression influences the progression of human breast cancer in a p53-dependent manner. J Exp Med 189:1381-1389.

Maynard Ma, Ohh Michael. 2004. von Hippel-Lindau tumor suppressor protein and hypoxia-inducible factor in kidney cancer. Am J Nephrol 24:1-13.

Petursdottir ThE, Hafsteinsdottir SH, Jonasson JG, Moller PH, Thorsteinsdottir U, Huiping C, Egilsson V, Ingvarsson S. 2002. Loss of heterozygosity at the FHIT gene in different solid human tumours and its association with survival in colorectal cancer patients. Anticancer Res 22:3205-3512.

Richards RI. 2001. Fragile sites and unstable chromosomes in cancer: causes and consequences. TIG 17:339-345.

Sard L, Accornero P, Tornielli S, Delia D, Bunone G, Campiglio 
M, Colombo MP, Gramegna M, Croce CM, Pierotti MA, Sozzi G. 1999. The tumor-suppressor gene FHIT is involved in the regulation of apoptosis and cell cycle control. Proc Natl Acad Sci USA 96:8489-8492.

Siprashvili Z, Sozzi G, Barnes LD, McCue P, Robinson AK, Eryomin V, Sard L, Tagliabue E, Greco A, Fusetti L, Schwartz G, Pierotti MA, Croce CM, Huebner K. 1997. Replacement of Fhit in cancer cells suppresses tumorigenicity. Proc Natl Acad Sci USA 94:13771-13776.

Smith SA, Easton DF, Evans DG, Ponder BA. 1992. Allele losses in the region $17 q 12-21$ in familial breast and ovarian cancer involve the wild type chromosome. Nat Genet 2:128-131.

Szeles A, Yang Y, Sandlund AM, Kholodnyuk I, Kiss H, KostAlimova M, Zabarovsky ER, Stanbridge E, Klein G, Imreh S. 1997. Human/mouse microcell hybrid based elimination test reduces the putative tumor suppressor region at $3 \mathrm{p} 21.3$ to $1.6 \mathrm{cM}$. Genes Chromosomes Cancer 20:329-336.

Vignal A, Gyapay G, Hazan J, Nguyen S, Dupraz C, Cheron N, Becuwe N, Tranchant M, Weissenbach J. 1993. Non-radioactive multiplex procedure for genotyping of microsatellite markers. In: Adolph KW, editor. Methods in molecular genetics; gene and chromosome analysis. San Diego, CA: Academic Press. p 211-221.

Werner NS, Siprashvili Z, Fong LY, Marquitan G, Schroder JK,
Bardenheuer W, Seeber S, Huebner K, Schutte J, Opalka B. 2000. Differential susceptibility of renal carcinoma cell lines to tumor suppression by exogenous Fhit expression. Cancer Res 60: $2780-2785$.

Yang Y, Kiss H, Kost-Alimova M, Kedra D, Fransson I, Seroussi E, Li J, Szeles A, Kholodnyuk I, Imreh MP, Fodor K, Hadlaczky G, Klein G, Dumanski JP, Imreh S. 1999. A 1-Mb PAC contig spanning the common eliminated region 1 (CER1) in microcell hybrid-derived SCID tumors. Genomics 62:147-155.

Yang Y, Alimova MK, Ingvarsson S, Qianhui Q, Kiss H, Szeles A, Cuthbert A, Klein G, Imreh S. 2001. "Elimination test (Et)" identifies similar 3 p regions, including CER1 at 3p21.3, in the human/human and in human/mouse microcell hybrid derived tumors. Proc Natl Acad Sci USA 98:1136-1141.

Yang Y, Li JF, Szeles A, Imreh MP, Kost-Alimova M, Kholodnyuk I, Fedorova L, Darai E, Klein G, Imreh S. 2003. Consistent downregulation of human lactoferrin (LF) gene expressed in A9 murine fibrosarcoma cells, following tumor growth in SCID mice. Cancer Letters 191:155-164.

Zanesi N, Fidanza V, Fong LY, Mancini R, Druck T, Valtieri M, Rudiger T, McCue PA, Croce CM, Huebner K. 2001. The tumor spectrum in FHIT-deficient mice. Proc Natl Acad Sci USA 98: $10250-10255$. 